\title{
Review of Research on Wind-sand Hazards in China Railway
}

\author{
Chunxiao Xue*, Kaichong Li, Lingwei Kong \\ Northwest Research Institute Co., Ltd. of China Railway Engineering Corporation, Lanzhou 730000, Gansu, China \\ Email: 36230418@qq.com
}

\begin{abstract}
China is the country with the longest mileage in the construction of sandstorms in the world. The railway system is often affected by wind sand flow, which seriously affects the operation safety of trains. Firstly, this article introduces the formation mechanism, movement state, monitoring method and structural characteristics of the wind-sand flow. Then the sand hazard formation mechanism of railway embankments, cuts, bridges and culverts is explained based on aerodynamic performance. Moreover, the sand prevention measures are classified, and the advantages and disadvantages of various measures are discussed. Finally, two kinds of sand prevention and control systems are proposed in combination with the topography and regional wind-sand flow characteristics, and the problems that need to be solved urgently in the prevention and treatment of railway sand and sand disasters in the future are prospected.
\end{abstract}

Keywords: railway wind-sand disaster, formation mechanism, engineering measures

\section{Introduction}

Wind sand disaster is a kind of secondary wind disaster caused by wind-blown sand, which involves many industries, especially the railway industry. As the country with the longest railway mileage in windy and sandy areas in the world, China's railway system is often attacked by wind-blown sand currents, which seriously affects the safe operation of trains. It takes a lot of manpower, material and financial resources to control the sand damage every year. Railways in China's sandstorm areas are mainly distributed in Xinjiang, Inner Mongolia and Tibet in Northwest China, involving more than 20 operating lines, including Lanxin high-speed railway, Lanxin railway, Halou railway, Nanjiang railway, Qinghai-Tibet railway, lari railway, Lince railway, etc ${ }^{[1-5]}$. These areas have strong wind force and abundant sand sources, which have the dynamic conditions and material basis for the formation of wind-blown sand.

The railway sandstorm disaster may pollute the track bed, block the bridge and culvert, destroy the signal system, or lead to the train derailment, or even overturn the train. In view of the railway sandstorm disaster, scholars and engineers have obtained a lot of research results through numerical simulation ${ }^{[6-7]}$, wind tunnel test ${ }^{[8-9]}$ and field monitoring ${ }^{[10-12]}$, and put forward some treatment schemes. Some schemes have been successfully applied in practical projects, and the protection effect is good. However, because the prevention and control of railway sand damage involves many disciplines such as aerodynamics, physics, ecology, chemistry and geotechnical engineering, it is a complex system engineering, so there are many deficiencies in the control of railway sand damage.

In recent years, with the western development strategy and the continuous improvement of the national road network, a number of new railways have been put on the agenda, such as the Lalin railway, Geku railway, Dunge railway, Heruo railway, and Jiue railway, which pose new challenges to the prevention and control of railways in the sandstorm areas, especially the Heruo railway crossing the Taklimakan Desert ${ }^{[13-15]}$.

On the basis of previous studies, this paper systematically analyzes the principles, advantages and disadvantages and applicable conditions of the prevention and control measures of railway sand disaster, and discusses the future development trend, so as to provide reference for the research and prevention of railway sand disaster in sand area.

\section{Wind-blown sand}

\subsection{Formation mechanism and movement form of wind-blown sand}

Wind-blown sand is a typical gas-solid two-phase flow. Wind is the dynamic condition and sand is the material basis. In the process of starting, sand needs to obtain energy from the air, so it needs certain wind conditions from static to moving. When the incoming wind speed increases to a certain critical value, the sand particles will enter the moving state from the static state. Generally, the critical wind speed at which the sand particles begin to move is called the starting wind speed, and all winds greater than the starting wind speed are called the starting wind speed. 
The starting mechanism of sand in wind environment can be summarized into six theories: differential pressure starting theory, wind pressure starting theory, impact starting theory, vibration starting theory, sudden starting theory and sliding starting theory. The representative is the theory of wind pressure starting proposed by Bagnold. He obtained the formula of the critical wind speed of coarse sand particles by analyzing the stress of sand particles on the bed surface ${ }^{[16]}$ :

$$
U_{*_{t}}=A \sqrt{\frac{\rho_{s}-\rho}{\rho} g d}
$$

Where: $U_{*_{\mathrm{t}}}$ is the critical friction velocity $(\mathrm{m} / \mathrm{s}) ; \rho_{\mathrm{s}}$ is the particle density $\left(\mathrm{kg} / \mathrm{m}^{3}\right) ; \rho$ is the gas density $\left(\mathrm{kg} / \mathrm{m}^{3}\right) ; \mathrm{G}$ is the acceleration of gravity $\left(\mathrm{m} / \mathrm{s}^{2}\right)$; D is the diameter of sand $(\mathrm{mm})$; $\mathrm{A}$ is the empirical coefficient.

Bagnold thinks that there are three main movement forms of aeolian sand flow: creep, saltation and suspension. Many scholars have also studied the collision process between saltation sand and bed surface through high-speed photography, and found that some saltation sand splashed some sand particles with lower saltation height after collision with bed surface, which is called saltation.

\subsection{Structural characteristics of regional wind-blown sand}

The structural characteristics of aeolian sand flow refer to the vertical distribution characteristics of sand particles carried by the airflow, which can provide the basis for the design of aeolian sand disaster prevention and control. Because the formation of wind-blown sand is mainly affected by wind environment and underlying surface conditions, the structural characteristics of aeolian sand flow have strong regional characteristics. Figure 1a shows the percentage of sand collection at different heights of wind-blown sand in Plateau and Gobi regions. It can be seen that the sand content in aeolian sand flow decreases with height, that is, the higher the height is, the smaller the sand content is. Figure $1 \mathrm{~b}$ shows the cumulative percentage of sand collection at different heights of wind-blown sand in the plateau and Gobi regions. It is not difficult to find that the sand collection below $1.0 \mathrm{~m}$ height in the plateau region accounts for more than $90 \%$ of the total sand collection, while the sand collection at about $2 \mathrm{~m}$ height in the Gobi Region of Xinjiang reaches more than $90 \%$ of the total sand collection. This indicates that the height of sand control measures should be $2 \mathrm{~m}$ in Gobi area and $1 \mathrm{~m}$ in plateau area ${ }^{[17]}$.

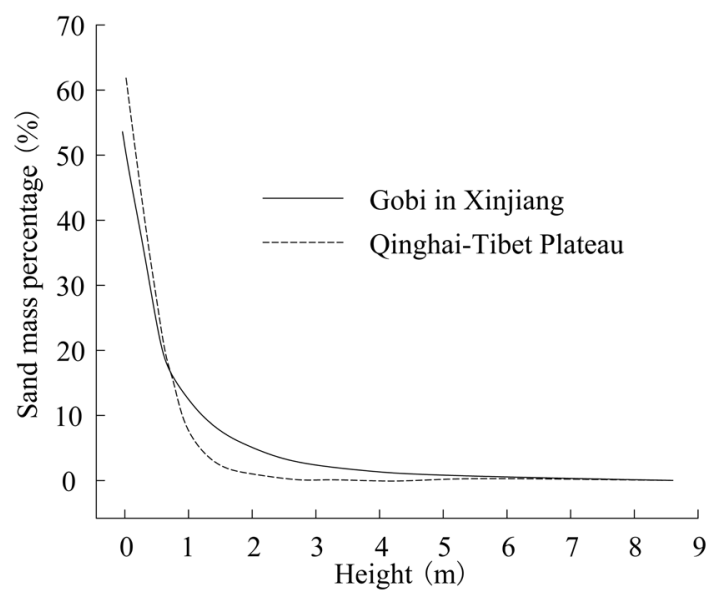

(a) Sand mass percentage

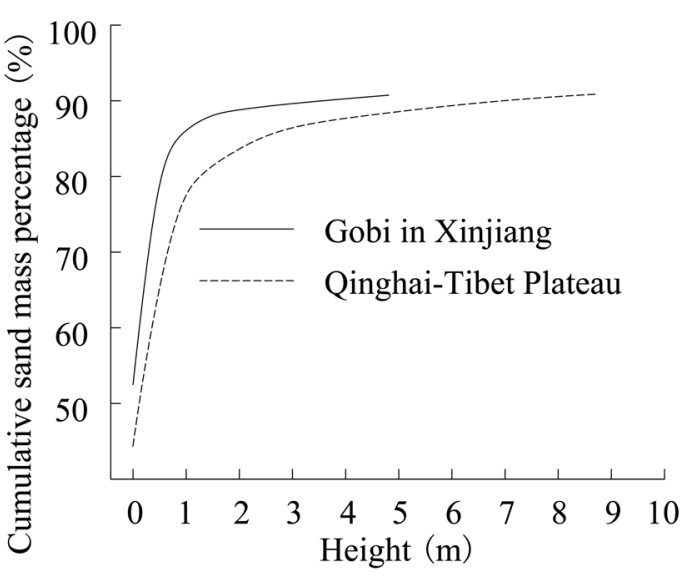

(b) Cumulative sand mass percentage

Figure 1. Percentage of sand accumulation at different heights

\section{Engineering measures for railway sandstorm disaster}

Since the beginning of sand control on Baotou Lanzhou Railway in the 1960s, Chinese scientific and technological workers have been exploring efficient railway sand control measures, and have developed dozens of sand barriers from various angles. According to the different functions of sand control, it can be roughly divided into four categories: sand fixation measures, sand resistance measures, sand diversion measures, sand cleaning measures and combined measures ${ }^{[18-25]}$.

\subsection{Sand fixation measures}

Sand fixing measures are mainly to increase the surface roughness and consume the energy of near surface airflow, so as to reduce the sand carrying capacity of airflow and the amount of wind erosion on the surface, so as to stabilize the sand 
source (Figure 2). According to the size of the regional wind speed and material properties, the conventional height is set between $20-50 \mathrm{~cm}$, the plane layout is square or rhombus, the side length is mostly $1 \times 1 \mathrm{~m}, 2 \times 2 \mathrm{~m}$, and the regional dominant wind direction is perpendicular to the side length direction. According to different construction materials, sand fixation measures can be further subdivided into the following categories:

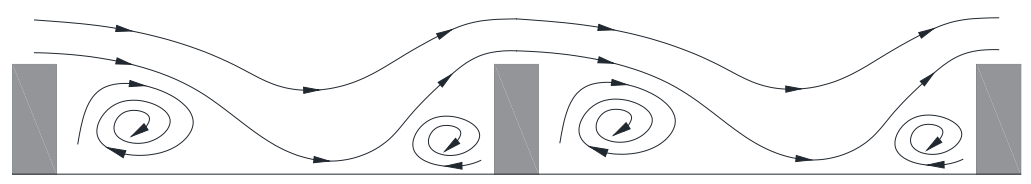

Figure 2. Airflow streamline in sand fixing measures with square grid

\subsubsection{Sand fixation with reed grid}

The reed grid sand fixation measures are shown in Figure 3a. Among them, some are buried underground and some are exposed to the surface. This measure is generally used in quicksand areas, with the characteristics of convenient construction, green environmental protection, high sand fixation efficiency, but in desert areas, reed materials are relatively scarce, and fire prevention is also a prominent problem in the process of construction and transportation.

\subsubsection{Sand fixation with stone squares}

The stone lattice sand barrier is mainly composed of pebbles or blocks (Figure 3b). This measure is generally used in areas with rich stone materials, and has the characteristics of green environmental protection, convenient construction, low cost, good durability, strong wind resistance, etc., especially in the Gobi area, such as Lanxin high-speed railway and Dunge railway. But there are also the following shortcomings, because the stone checkerboard sand barrier is mainly constructed by human, and the stone size, shape and other differences, resulting in the uneven level of sand control efficiency, some measures even did not achieve the desired goal. In order to improve the stability of sand control efficiency, mechanized construction is the development trend.

\subsubsection{Sand fixation with concrete grid}

The height and plane size of the concrete grid are determined according to the characteristics of regional sand flow (Figure 3c). It has the characteristics of convenient construction, strong wind resistance and good durability. In addition, two handles are prefabricated above each concrete slab. When the sand accumulation in the grid reaches a certain height, resulting in the reduction of sand fixation efficiency, the concrete slab can be pulled up to improve the sand fixation efficiency, so that the circular operation can achieve the purpose of reuse. But this measure has the disadvantages of complicated production process and high project cost.

\subsubsection{HDPE grid sand fixation}

HDPE grid sand fixing measures are mainly composed of HDPE grid and column. During the construction process, the column is inserted into the ground, and then the net is fixed on the column, and finally the HDPE grid sand barrier is formed (Figure 3d). This measure has the characteristics of low cost and high sand fixation efficiency, but the construction is cumbersome, the wind resistance is poor, and the service life is short. In addition, due to the great difference in the material quality of HDPE network in the market, the HDPE network along the railway has been used for less than a year, and it has lost its sand fixation function due to strong wind. Therefore, the selection of HDPE materials and quality inspection is the key to its construction control.

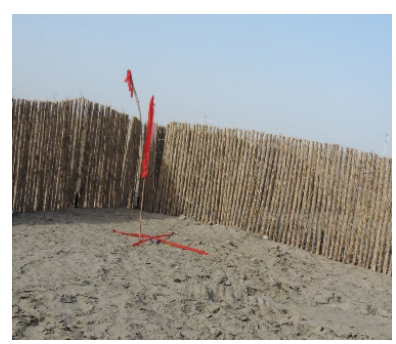

(a) Reed grid

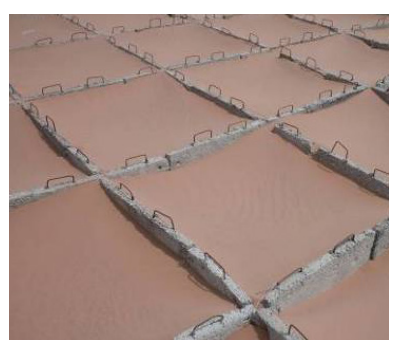

(b) Stone squares

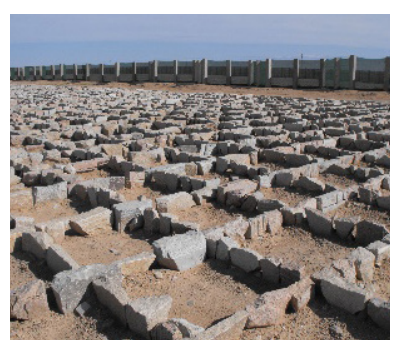

(c) Concrete grid

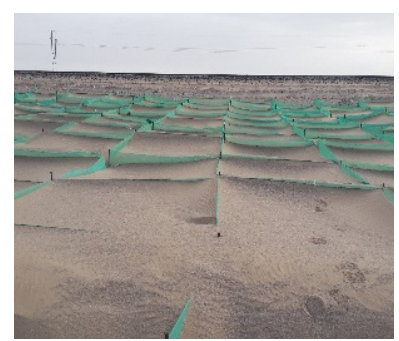

(d) HDPE grid

Figure 3. Sand fixation with reed grid along railway 


\subsection{Sand control measures}

The main purpose of sand control measures is to make part of the sand particles in the passing sand flow deposit around it, so as to purify the passing sand flow and reduce the sand particles deposited on the railway. When the airflow passes through the sand control measures, the local attenuation of the surrounding wind speed and the recirculation of the airflow are the key reasons for the sand deposition (Figure 4). But when the height is given, the dimension, porosity, pore shape and pore distribution of sand control measures are the key factors affecting the sand control effect. Based on this, sediment control measures can be roughly divided into the following categories:

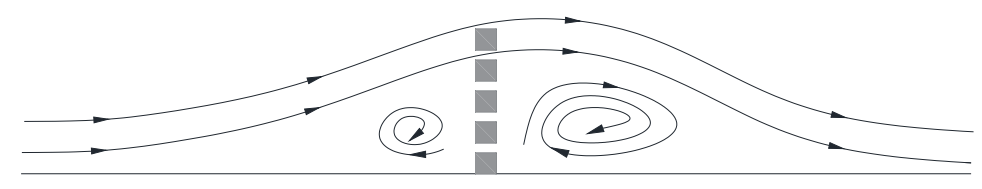

Figure 4. Airflow streamline around sand control measures

\subsubsection{Classification based on dimension}

According to the dimension of sediment control measures, they can be approximately divided into two-dimensional measures and three-dimensional measures (Figure 5). The two-dimensional measure is similar to the plane, and the thickness direction is much smaller than the size of the other two directions, while the three-dimensional measure section is generally trapezoidal, which is similar to the embankment or the combination of cutting and embankment, and the thickness and height direction are much smaller than the length direction. Two dimensional measures generally use artificial materials, such as reinforced concrete, wood, steel, HDPE, etc., while three-dimensional measures generally use local materials, such as clay or pebble soil. The aerodynamic performance of three-dimensional measures shows that the slope ratio is the key factor affecting the sand control performance, and the steeper the slope is, the better the sand control efficiency is. But when the height is fixed, the sand control performance of three-dimensional sand control measures is far lower than that of two-dimensional sand control measures. Therefore, it is not recommended to use three-dimensional sand control measures except for the sections with slight wind and sand disasters. In addition, it is worth noting that adding two-dimensional measures on top of three-dimensional sand control measures is an effective means to improve the efficiency of sand control.

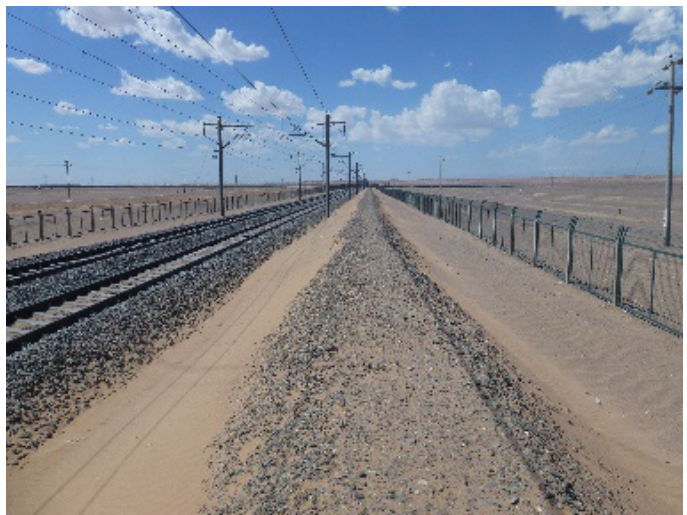

(a) Three dimensional

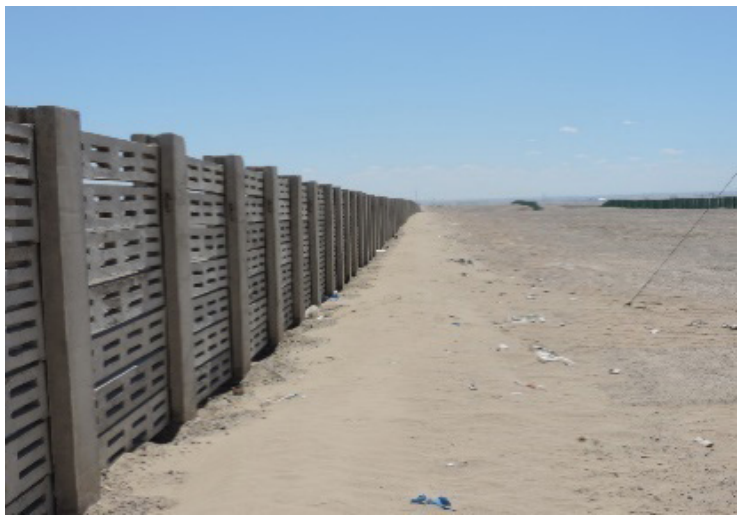

(b) Two dimensional

Figure 5. Classification of sediment control measures based on dimension

\subsubsection{Classification based on pore uniformity}

According to the uniformity of pores, sediment control measures can be divided into two categories: uniform pore sand control measures and non-uniform pore sand control measures (Figure 6). HDPE net sand control is one of the most widely used sand control measures with uniform pores. It has the characteristics of high sand control efficiency and low engineering cost, but it has weak wind resistance and poor durability. In addition, metal coated plastic mesh and punched steel plate are also uniform pore sand resistance measures, but due to the high cost of the project, they are only used in some lines. The former is used in Lanxin high-speed railway, and the latter is used in Lari railway. 


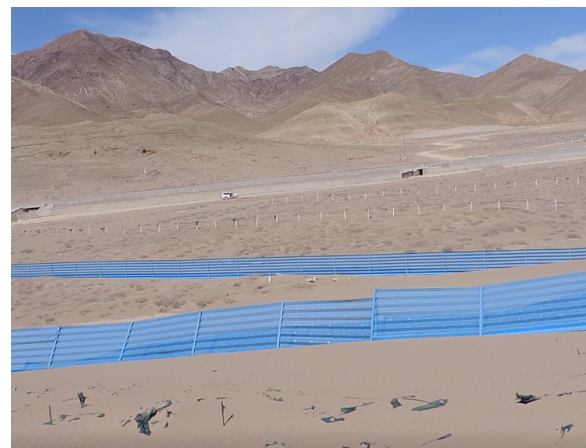

(a) Punching steel plate

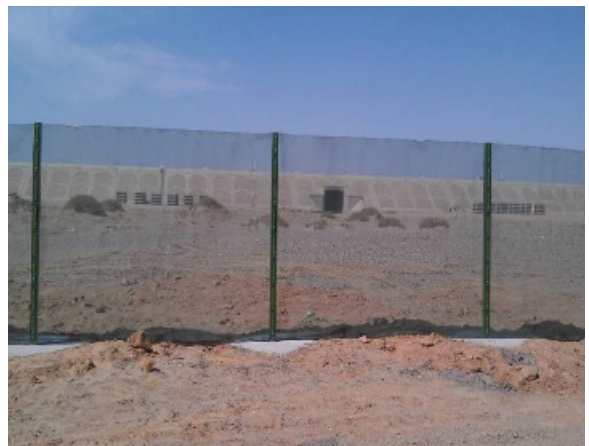

(b) Metal coated plastic mesh

Figure 6. Measures for sand resistance of punching steel plate

There are many kinds of non-uniform pore sand control measures, which can be divided into the following types according to the form of pore: plug plate, hanging plate, bell type, inclined plug plate, box type and sleeper type (Figure 7). When the height and porosity are given, the order of sand control efficiency from high to low is as follows: inclined inserted plate $>$ box type $>$ sleeper type $>$ hanging plate $>$ inserted plate $>$ bell type. Among them, the sleeper type uses the waste sleepers to construct sand resistance measures, which can be used only in special sections, but the number of used sleepers is limited, and the rest types of sand control measures are constructed by prefabrication and assembling on site. It is worth noting that the construction materials of the above sand control measures are generally concrete, which has the characteristics of strong wind resistance and good durability. However, in addition to the optimization design of inclined insert plate, there is no relevant literature on the optimization research results of other types of measures, so there is a certain blindness in the design.

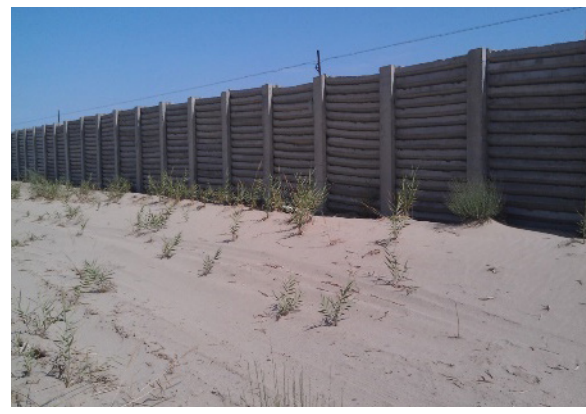

(a) Inclined inserting plate

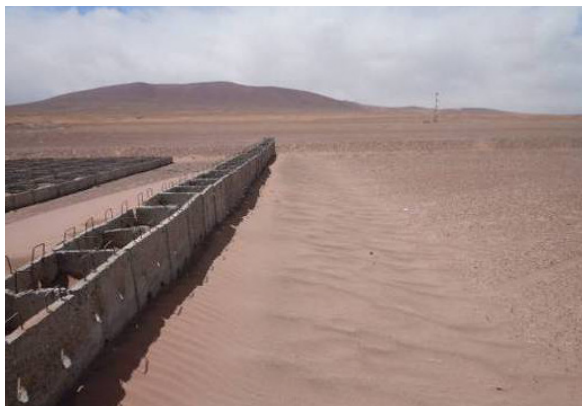

(b) Box type

Figure 7. Sediment control measures with non-uniform pores

\subsection{Sand guiding measures}

The purpose of sand guiding measures is to change the local wind direction by means of the measures, so as to guide the wind sand flow to move along the guiding direction (Figure 8). But in fact, the wind direction is changeable and the terrain is undulating, so it is difficult to achieve the expected effect, so it is only implemented in the test section along the Qinghai Tibet railway.

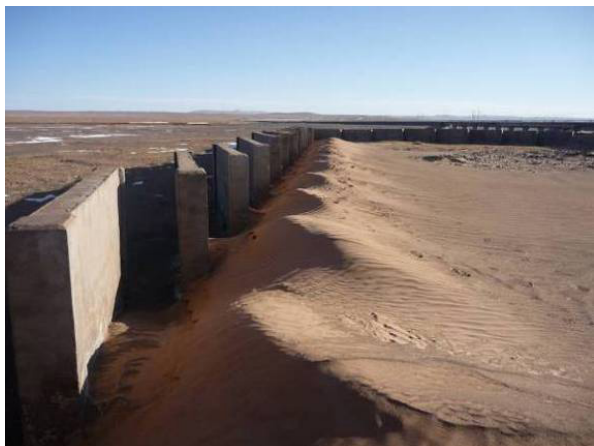

Figure 8. Sand guiding measures 


\section{Prevention and control system of railway sand disaster}

Practice has proved that it is difficult to achieve the desired goal by only one sand control measure. It is necessary to combine the above measures to form a three-dimensional sand control system to achieve satisfactory results. According to different topography and landform, combined with the regional wind and sand environment, two kinds of wind sand protection system are proposed in this paper from the big environment for reference.

(1) Gobi region

Because the Gobi area is mainly the transit wind sand flow, that is, the sand source mainly comes from the upwind, and the local sand source is less. It is suggested that multi-channel sand blocking measures should be adopted on the outermost side to intercept the external sand source, and sand fixation measures should be adopted on the inner side to fix the local sand source.

(2) Desert area

Local sand source is the main source in desert area. It is suggested that sand fixation measures should be taken as the main and sand blocking measures as the auxiliary. That is to say, sand fixation measures should be used in a large area to achieve the purpose of fixing the local sand source, and sand blocking measures should be set on the sand ridge line of sand dunes to prevent the rapid movement of mobile sand dunes.

In addition, according to the actual situation along the railway, some scholars put forward several typical wind sand protection systems, but they are all suitable for specific wind sand environment, and should not be applied step by step. It needs specific analysis of specific problems to achieve the best effect. For example, the successful protection system of "five belt integration" of Baolan railway lies in the proximity to the Yellow River, abundant water resources and convenient irrigation.

\section{Summary and prospect}

To sum up, the construction and operation of aeolian sand railway has been promoting the progress of sand control technology, and remarkable achievements have been made. The above research results have laid a good foundation for the prevention and control of railway sand disaster. However, there are also some shortcomings:

(1) The performance of sand control measures is not fixed value, but decreases with the increase of sediment deposition around, even loses the effect of sand control, but the existing research results do not consider this problem;

(2) There are many kinds of sand control measures, but the optimization of design parameters for a certain measure is very few, which leads to great blindness in the process of railway sand disaster design;

(3) HDPE network measures are widely used, but lack of unified testing standards and methods, resulting in the uneven quality level of materials, resulting in the service life of the measures is far less than the design life.

Therefore, in the future research, we should strive to solve the above problems, so as to make the prevention and control of sandstorm disaster targeted.

\section{References}

[1] Li Kaichong, Jiang Fuqiang, Xue Chunxiao, et al. Characteristics of gobi sand -drift along south Xinjiang railway. Journal of Arid Land Resources and Environment. 2011; 25(5): 67-71.

[2] Zhang Kecun, Qu Jianjun, Yao Zhengyi, et al. Sand damage and its control along the Golha Section of the Qinghai-Tibet Railway. Arid Land Geography. 2014; 37(1): 74-80.

[3] Ge Shengchang, Jiang Fuqiang. Analyses of the Causes for Wind Disaster in Strong Wind Area along Lanzhou-Xinjiang Railway and the Effect of Windbreak. Journal of Railway Engineering Society. 2009; 128(5): 1-4.

[4] Xie Shengbo, Qu Jianjun, Lai Yuanming, et al. The causes, distributions, characteristics of sand hazards and its controls for Lhasa-Shigatse Railway. Journal of Arid Land Resources and Environment. 2016; 30(2): 170-175.

[5] Luo Xinwen. Discussion on formation causes and prevention and treatment measures of sand-disasters for Linhe-Ceke railway. Railway Engineering. 2012; 11: 95-97.

[6] Hao Xiaojie, Xiong Zhiwen, Jiang Fuqiang, et al. Research on the Positions of Various Kinds of Sand Barriers in Qinghai-Tibet Railway. Railway Standard Design. 2012; (4): 16-20.

[7] Li Chi, Gao Yu, Huang Hao, et al. Numerical simulation of wind erosion damage rules for desert highway. Rock and Soil Mechanics. 2011; 21(1): 642-647.

[8] Zhang Kecun, Niu Qinghe, Qu Jianjun, et al. Study on the Characteristics of Flow Field and the Mechanism of Windblown Sand Disasters in the Tuotuohe Region along the Qinghai-Tibet Railway. Arid Zone Research. 2012; 27(2): 303308.

[9] Li Kaichong, Xue Chunxiao, Liu Heye, et al. Wind Tunnel Test on Sand-preventing Mechanism of Different Kinds of 
Sand-barriers. Journal of Railway Engineering Society. 2015; 196(1): 17-21.

[10] Jiang Fuqiang, Li Ying, Li Kaichong, et al. Study on Structural Characteristics of Gobi Wind Sand Flow in $100 \mathrm{~km}$ Wind Area along Lan-Xin Railway. Journal of the China Railway Society. 2010; 32(3): 105-110.

[11] Li Kaichong, Jiang Fuqiang, Xue Chunxiao, et al. Analysis of the Characteristics of Gobi Sand-driving wind in Shisanjianfang Section of Lanzhou-Xinjiang Railway. Journal of Railway Engineering Society. 2010; 138(3): 15-18.

[12] Zhang Kecun, Qu Jianjun, Zu Ruioing, et al. Research on the Characteristics of Structure of Drifting Sand Flux and Wind Velocity Profile over Gobi. Research of Soil and Water Conservation. 2005; 12(1): 54-58.

[13] Yao Hongle. The Blown Sand Characteristics and Sand Hazards Comprehensive Protective System at the Sand Dune Areas along the Dun-Ge Railway. Journal of Desert Research. 2015; 35(3): 555-564.

[14] Chang Xiaobo. Study on Sand Dike through Wind Tunnel Numerical Simulation Test and Sand Pile Test on Jiuquan to EJiNa Railway. Railway Standard Design. 2017; 61(5): 1-5.

[15] Wang Shuang, Cui Xiaoning, Liang Kexin. Causes of Sand Damage and Its Control Measures in Qinghai Section of Golmud-Korla Railway. Railway Engineering. 2019; 59(7): 1-5.

[16] Bagnold R A. The Physics of Blown Sand and Desert Dunes. London: Methuen; 1941.

[17] Li Kaichong, Xue Chunxiao, Jiang Fuqiang, et al. Research on the Different Characteristics of Sand-drift between Gobi and Plateau. Journal of Railway Engineering Society. 2014; 190(7): 7-11.

[18] Xue Chunxiao, Jiang Fuqiang, Cheng Jianjun, et al. Research on Sand Preventing Benefit of Sand Retaining Wall in a Strong Wind Sector along Lanzhou-Xinjiang Railway. Journal of Glaciology and Geocryology. 2011; 33(4): 859-862.

[19] Ge Chungen, Shi Long, Li Kaichong. Benefit Evaluation of Sand Prevention Measures in Strong Wind Area along Second Lanzhou-Xinjiang Railway. Railway Standard Design. 2015; 59(9): 37-40.

[20] Liu Shihai, Feng Lingzheng, Xu Yaoyi. Study on Effect of Wind Erosion Controlling in the Geerm-Lahsa Section of the Qinghai-Tibet Railway. Journal of the China Railway Society. 2010; 32(1): 133-136.

[21] Li Shunping, Jiang Fuqiang, Xue Chunxiao, et al. Field Investigation of Sand Disaster and Prevention Research on the Golmud-Lhasa Section of Qinghai-Tibet Railway. Journal of Railway Engineering Society. 2014; 188(5): 1-6.

[22] Xue Zhide, Liu Shihai, Xu Zhaoyi, et al. Efficiency of wind erosion control measures along Cuona Labe on Qinghai-Tibet railway, western China. Journal of Beijing Forestry University. 2010; 32(6): 61-65.

[23] Shi Long, Jiang Fuqiang. Numerical Simulation on Parameters Optimization of the Oblique Inserting Plate Retaining Sand Wall Design. Journal of Desert Research. 2014; 34(3): 666-673.

[24] Han Feng, Shi Long, Li Kaichong. Response Law of Wind-Sand Flow to Windbreak Wall along Lanzhou-Xinjiang High Speed Railway. China Railway Science. 2019; 40(5): 9-15.

[25] Li Kaichong, Shi Long, Jiang Fuqiang. Research on the Relationship between Perforated Sand-blocking Wall and Sand-blocking Effect. Journal of Railway Engineering Society. 2017; 230(11): 5-9. 